\title{
Growing Existing Aboriginal Designs to Guide a Cross-Cultural Design Project
}

\author{
Margot Brereton ${ }^{1}$, Paul Roe ${ }^{1}$, Thomas Amagula ${ }^{2}$, Serena Bara ${ }^{2}$, \\ Judy Lalara ${ }^{2}$, and Anita Lee Hong ${ }^{1}$ \\ ${ }^{1}$ Queensland University of Technology, ${ }^{2}$ Anindilyakwa Land Council \\ $\{\mathrm{m}$. brereton, p.roe, anita. leehong $\}$ equt. edu . au
}

\begin{abstract}
Designing across cultures requires considerable attention to interrelational design methods that facilitate mutual exploration, learning and trust. Many Western design practices have been borne of a different model, utilizing approaches for the design team to rapidly gain insight into "users" in order to deliver concepts and prototypes, with little attention paid to different cultural understandings about being, knowledge, participation and life beyond the design project. This paper describes a project that intends to create and grow a sustainable set of technology assisted communication practices for the Warnindilyakwa people of Groote Eylandt in the form of digital noticeboards. Rather than academic practices of workshops, interviews, probes or theoretical discourses that emphasize an outside-in perspective, we emphasize building upon the local designs and practices. Our team combines bilingual members from the local Land Council in collaboration with academics from a remote urban university two thousand kilometers away. We contribute an approach of growing existing local practices and materials digitally in order to explore viable, innovative and sustainable technical solutions from this perspective.
\end{abstract}

Keywords: Cross-cultural, Aboriginal, slow design, sustainable design, digital noticeboards, urban screens, interface design, Human-computer interaction.

\section{Introduction}

Aboriginal communities in Australia see great potential for technologies to engage their youth, preserve their language, strengthen their culture and assist their communication within and outside their communities. The Anindilyakwa Land council of Groote Eylandt together with academic researchers has embarked upon a project to design "digital noticeboards" suited to and in service of the Warnindilyakwa people to support bilingual communication about news, culture, health, education etc. However, effective introduction of technology in a remote community requires consideration of how it will fit and thrive amidst the everyday practices of the Warnindilyakwa.

In this paper we examine design practice across cultures in general and then introduce the Warnindilyakwa people of Groote Eylandt. We then explain our research approach for the context of Groote Eylandt. This provides the background for our approach of extending existing Indigenous designs digitally in order to (a) best 
engage the expertise, cultural knowledge and aspirations of the local people and (b) demonstrate technological possibilities in a concrete and culturally relevant way.

\section{Design Practice across Cultures}

There is recent recognition of the problem of design practices not translating across different cultures and settings [6,14]. Winschiers demonstrated that common Western Participatory Design (PD) methods such as workshops and brainstorming were incompatible with the socio-cultural habits of Namibian participants [14]. Irani et al [10] argued that methods are transnationally produced and dynamic, and we can expect that problems will arise if methods are assumed to move easily and stably from one setting to another. Irani et al call for embracing heterogeneity in design, thinking about design in terms of engagements between different groups, the complexities of articulating perspectives and implications of translation between sites.

Brereton and Buur [5], in moving beyond the idea of users and defined participant groups, found that "new formats of participation can be characterized by their sensitivity towards new types of networked relations among people, the diverse motivations of people to participate, the subtle balance of values and benefits involved in collaborative endeavours and the inherent power relations between participants".

Different cultures have understandings about being, knowledge, participation and life. Winschiers et al [15] in the African context also found it is more useful to emphasize communities than individual users. In Sub-saharan Africa, "the way of life is deeply rooted in a paradigm of 'connectedness of all' expressed in the aphorism, 'a person is a person through other people" "[15]. When participation is already a core value in a community, the role for researchers engaging in design with a community is to read and respond to community practices and way of life such that they themselves become "participated".[15] There is thus recognition among engaged design practitioners in developing contexts that hybrid practices in technology design must emerge that are sensitive to the contexts and networks of relations at hand. Moreover understanding of the evolving context and networks of relations takes time to develop and hence design is worth growing over time [3].

\section{Groote Eylandt and the Warnindilyakwa People}

The Groote Eylandt Archipelago is a unique and diverse environment in the Gulf of Carpentaria off the northern coast of Australia; it is the traditional homeland of the Warnindilyakwa people. The Warnindilyakwa people were brought to Groote Eylandt on a series of songlines [16] which created the land, rivers, animals and people and which named everything pertaining to the region. The language, "Anindilyakwa" is spoken by the 14 clan groups, which make up the two Moieties on Groote Eylandt. There are approximately 1400 Warnindilyakwa people living in three communities, and they are all formally related. Traditional collective culture governs much of the Warnindilyakwa people's lives, but people in this region endeavour to "combine a 
traditional lifestyle with the comforts of the 21st century" [7] building upon the opportunities presented largely by manganese mining and tourism.

The history of Groote Eylandt has changed dramatically over the past century [8], with a nomadic lifestyle and oral culture replaced by a more Western one bringing many problems as well as benefits. The cumulative effects of long-term disengagement between governments and the three Anindilyakwa communities on Groote Eylandt has led to poor comparative socio-economic outcomes [7,8].

The Anindilyakwa Land Council (ALC) is a progressive land council that has initiated approaches across the spectrum to reconnect and re-engage the people of Groote. The executive membership consists of elected members, Elders from each of the 14 clans on the island. Contemporary challenges include: poor school attendance rates and declining engagement of youth in Warnindilyakwa culture, ceremony and history.

Fundamental to the ALC's initiatives is to seek ways of using technology within an Aboriginal context to support communication and connection on Groote. New digital technologies have the potential to address isolation problems leading to improved education, health and employment outcomes and improved cultural exchange and understanding [9]. Schools have adopted iPads in the classroom and many Aboriginal residents own iPads (over 100 owned by the 1400 residents).

With limited internet access, low literacy, an oral language tradition and a collective Aboriginal culture that is fighting to remain vibrant and sustainable, there is considerable work to do to understand how to best to support communication and connection through technologies. In summary, the Warnindilyakwa people seek to embrace the opportunities and challenges of the modern world by maintaining a firm footing in both Warnindilyakwa traditional culture and Western culture and seek to exploit technologies in order to do this. ${ }^{1}$

\section{A Research Approach for the Groote Context}

Groote Eylandt is a cultural and environmental jewel. As such the Warnindilyakwa have been extensively researched, often by fly in fly out researchers, with little perceived benefit to the community. It is important that new knowledge and technologies are owned by the people and that the project is sustainable: not an expensive toy. So in this project the team has tried to take a different approach to design "of the noticeboards" by growing existing design practises and thereby ensuring sustainability, familiarly and above all ownership of the project and its design by the community, building upon the ethos of Participatory Design as construed by Beck [1].

Previously we have we emphasized the importance of building relationships across cultures through the Aboriginal cultural practice of "yarning" and time spent together in hands on practical activities [4]. As academic researchers one of us was first

${ }^{1}$ For the purpose of definition, we take "culture" to simply mean the way of life of a group of people. People by virtue of their family history, environment, relations, hobbies and work may belong to many different cultures and sub-cultures. Particular design questions and participating groups tend to bring into focus different cultural perspectives. 
engaged in work on Groote to address the environmental threat of cane toad invasion, a non-native species that is a pest in Australia. This led to the deployment of environmental monitoring projects in collaboration with the local Indigenous Ranger groups. Such practical projects involve time spent together engaged in activities on country and in the lab and time out in tea breaks. This provides time for talking, noticing each other's different ways, and helping each other out. The digital noticeboard project was first conceived in this context: on country, yarning and with local designs.

With consent from the Elders who make up the Land Council Executive membership, the project was put to the Australian Research Council and approved. Having received funding to work together to develop a series of digital noticeboards, one might expect the workshops and design activities to begin. However, differences in cultures are such that even contemplating holding an event or workshop is revealing of a large number of unknowns, so much so that it becomes intuitively clear that a workshop is not the place to start. Moreover in a collective culture it is important to make sure that everyone feels included and that Elders guide the project.

As a first step the non-Anindilyakwa members of the project undertook a cross cultural course and spent much time speaking with different members of the community, other stakeholders and other Aboriginal Australians. Bi-cultural people (Anindilyakwa who have spent time off island in Western communities) proved immensely important in understanding issues and being able to relate them across cultures.

The project has proceeded through dialogue with the Elders to explain our current thinking and to seek suggestions and advice. Dialogue and activities have also taken place with the Linguistics Centre staff, the Indigenous Land and Sea Rangers, the School principals and other groups on the Island. Activities have included ecological monitoring, fishing with the Rangers, and much fixing of computers and transferring photos between iPads. This has given insights into issues using everyday technology.

The goal of our project is to research, design, build and evaluate novel public communal technologies harmonised to the Warnindilyakwa. It is important to understand who will use the noticeboards, where they will be placed, what form they will take (noticeboards, tabletops or other forms that emphasize orality [2]), what kinds of interaction modalities they will support, protocols for publishing content, how they will be maintained etc.

The Warnindilyakwa culture is so different from Western culture and there seems to be so much potential for mistakes that it is difficult to know where to start. So we start from an existing point, working together, researchers with bilingual Warnindilyakwa members of the Land Council, beginning with Warnindilyakwa designs.

\section{$5 \quad$ Warnindilyakwa Existing Design Practise}

The Warnindilyakwa have invested considerable time and resources into designing and producing several artefacts whose principal purpose is for communication, both within the community and to the outside world. These include:

1. A poster presenting the Anindilyakwa Indigenous Protected Area (IPA) [11];

2. The land council newsletter "Ayakwa" [12]; and

3. Photos, videos and maps. 


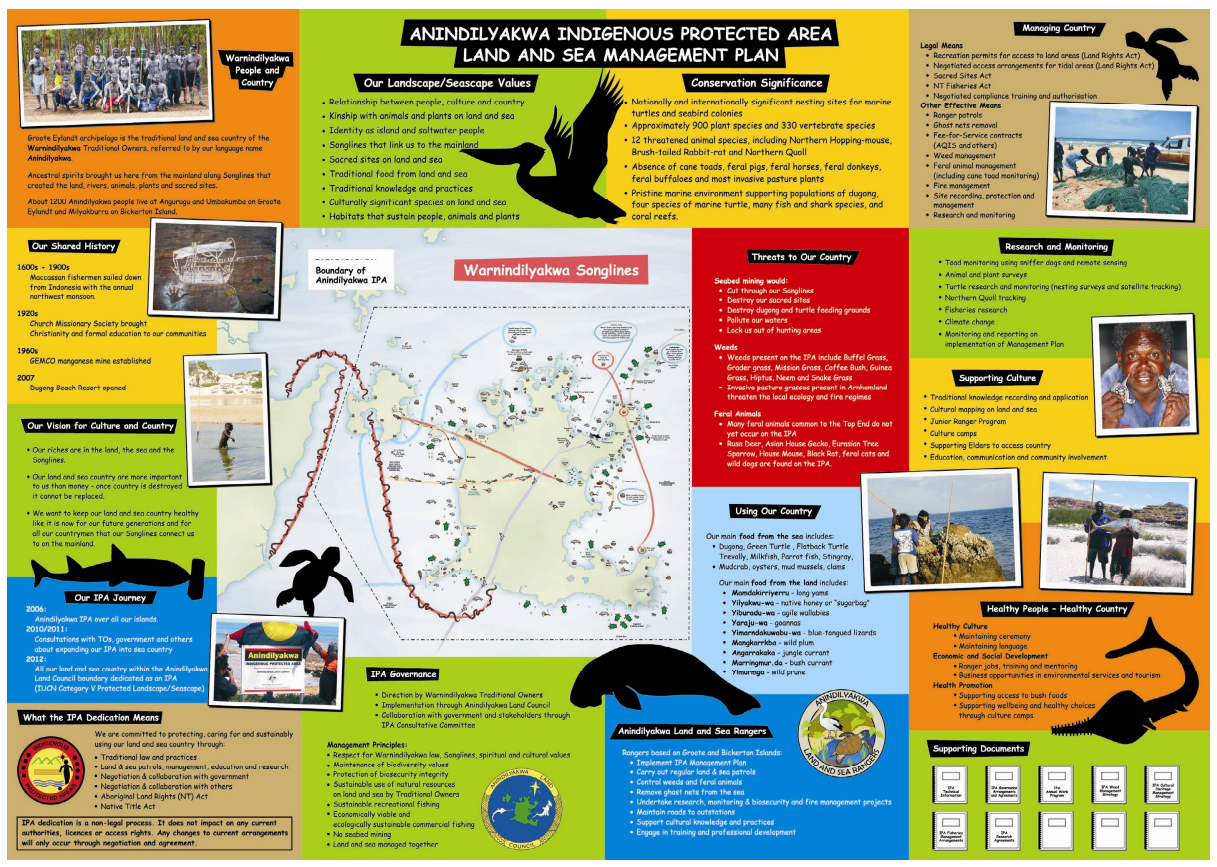

Fig. 1. Poster explaining the Groote Eylandt Indigenous Protected Area

The IPA poster (Fig. 1) was designed for communicating the importance of the Anindilyakwa Indigenous Protected Area agreement with the community and outside world. The IPA poster went through many iterations incorporating feedback from each of the different Warnindilyakwa clans. In particular the poster and its components required permission from Elders of each clan in order to be used and displayed.

The Ayakwa newsletter is a bi-monthly publication of the Anindilyakwa Land Council, see Fig. 2. The newsletter informs the community of news, event and important social messages. It is produced by the ALC and vetted by other members of the community before being published. Whilst being English text based the newsletter also contains stories "in language" and is highly visual.

Photos, videos and maps are used by the community, anthropologists, educators, health workers and rangers to discuss and present ideas. For example videos of ranger activities are shown to old people at aged care facilities both for their enjoyment but also to discuss issues, garner feedback and obtain permission. Videos have also been published for people remote from Groote to view on island activities [13].

\section{First Steps Towards Cross Cultural Design of Digital Artefacts}

Growing existing designs of the IPA poster, Ayakwa newsletter and maps and videos into digital and slightly interactive forms proved to be effective starting points for the 
design. We constructed digital versions of these which could be rendered on iPads (fairly common in the community), PCs and a large touch screen noticeboard which was shipped to the island. We stayed faithful to the original graphics and designs, with modifications to accommodate aspects such as screen size, interactive navigation and audio and video elements. The familiarity of the designs (IPA post, Ayakwa and ranger videos) enabled the community to immediately understand the potential of the interactive digital form, to begin generating further ideas and to discuss sensitivities.
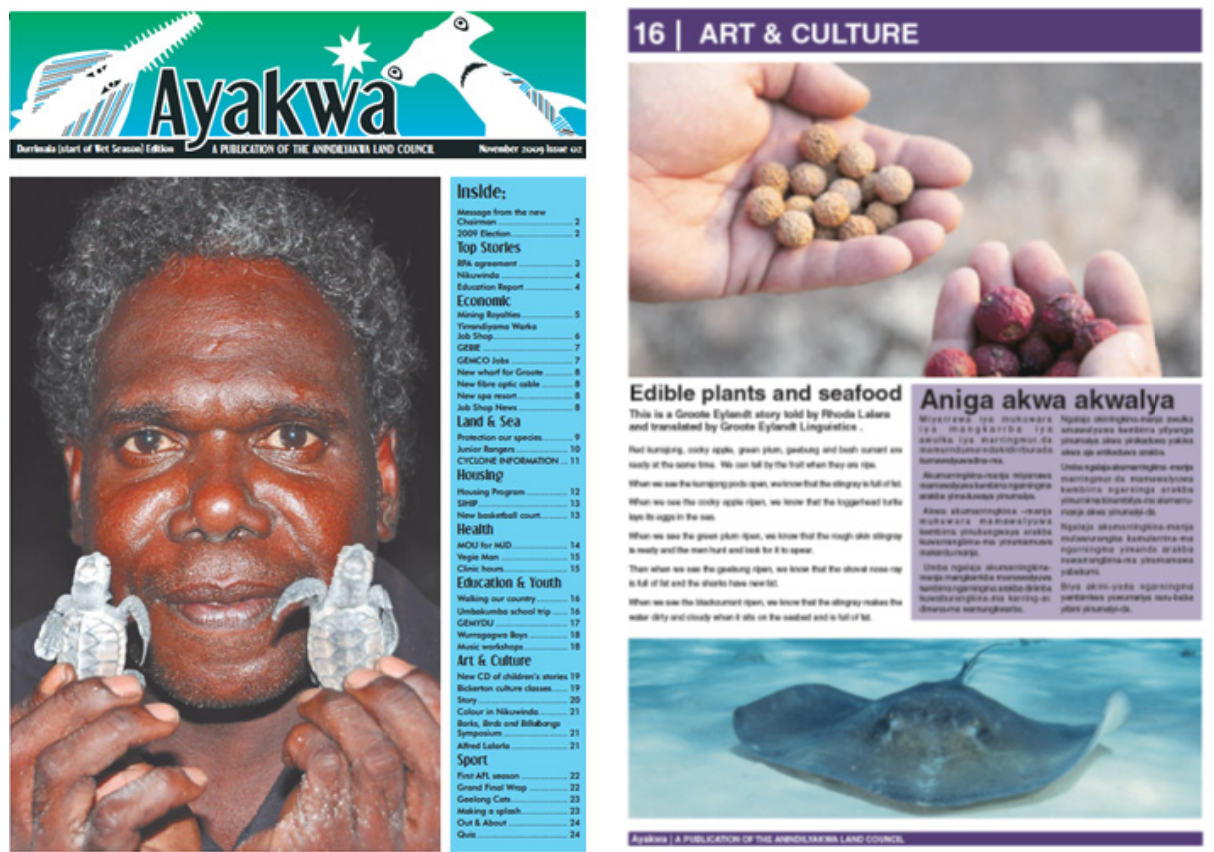

Fig. 2. Ayakwa newsletter

Working with the familiar respects community, what the community has done and puts them in control because they have all of the knowledge that surrounds those things. It also helps non-community members to tap into community design ideas.

Initially the University researchers had hypothesized that sophisticated permissions systems might be necessary to control access to digital material and to obtain permission: systems which understood clans and community relationships. In fact existing straightforward protocols already exist: the Elders of all the clans, or those concerned, decide. This became immediately apparent through understanding how existing artefacts had been designed. Furthermore by starting with and growing existing artefacts the team was able to immediately trial novel technologies, e.g. digital noticeboards, seeded with designs including images and videos for which permission had already been obtained. (Were the designs to be used outside a trial e.g. for publication on the web permission would need to be requested again.) 
It became clear for example from the initial demonstration of the digital noticeboard that the Elders were very pleased to be able to present positive stories from the Ayakwa magazine spoken "in language" on the digital noticeboard. At present these stories may not reach many in the community with low literacy. There was much discussion of subtitles and speaking in both Anindilyakwa and English languages, so as to foster literacy in English, and to further the correct spoken form of Anindilyakwa, reinforced by subtitles. The discussion revealed further concern about the way in which the design of some social media and texting practices encourages the use of creole, since they do not support oral forms, and because the written form of Anindilyakwa is quite long.

Showing a Google map of Groote Eylandt on the large touchscreen noticeboard led to proposals from the Elders for the possibility to show songlines, ecological names, clan estates and their boundaries and stories of the people, so that they can better impart and share their culture with the youth. It also revealed the quite different qualities between the Google map and a map created by an anthropologist, charting the names of the country according to the local people. The Elders were keen to enable these sorts of representations through technology.

From the conception of the project there have been different expectations and understandings of the project and different perspectives on what might or might not be acceptable regarding interfaces and publication. In a collective culture such as the Warnindilyakwa there are no leaders, the only consensus is on what Elders from all the clans might agree too. Some members of the community are keen to publish and promote culture to other parts of the world; others are more conservative.

The reaction of the non-Anindilyakwa was to avoid any cultural sensitivities and to initially target 'safe' aspects of the community life like the ranger program (environment) and sport. This proved both naïve and unnecessary: naïve in that culture pervades aspects of community life and unnecessary in that existing designs had already been undertaken and were ideal seeds from which to grow designs.

\section{In Conclusion}

Familiarity and expertise are key starting points that enable people to make design contributions. Building upon existing Indigenous designs and growing them into digital forms was an effective method of beginning a cross-cultural design project. It enabled the design team to engage the expertise and cultural knowledge of the local people and demonstrate technological possibilities in a concrete and culturally relevant way. In cross cultural design projects, approaches that respect cultural practices and learn from earlier local initiatives form an important stepping stone towards developing shared understandings and making greater innovations together.

Acknowledgements. First and foremost we wish to acknowledge the ALC, linguistics, rangers and Warnindilyakwa community for supporting this project. Elayne Fernandez, Vincent "Billy" Van Uitregt, Jason Wimmer, Joel Anderson and Ben Hall 
all provided valuable input, as did QUT students Monique Alvis and Bethany Ward. This work was supported by an Australian Research Council Linkage Research project number LP120200329.

\section{References}

1. Beck, E.E.: P for Political: Participation is not enough. Scandinavian Journal of Information Systems 14(1), 1 (2002)

2. Bidwell, N.J., Reitmaier, T., Marsden, G., Hansen, S.: Designing with mobile digital storytelling in rural Africa. In: Proceedings of the 28th International Conference on Human Factors in Computing Systems, pp. 1593-1602. ACM (April 2010)

3. Redhead, F., Brereton, M.: Growing local participation through long term design. In: Proceedings of the Participatory Innovation Conference 2012, Melbourne, pp. 1-4 (2012)

4. Brereton, M., Roe, P., Hong, A.: Evolving a relationship for cross-cultural participatory innovation. In: 2012 Participatory Innovation Conference Digital Proceedings, pp. 1-5. Swinburne University (2012)

5. Brereton, M., Buur, J.: New challenges for design participation in the era of ubiquitous computing. Co-Design 4(2), 101-113 (2008)

6. Puri, S.K., Byrne, E., Nhampossa, J.L., Quraishi, Z.B.: Contextuality of participation in IS design: a developing country perspective. In: Proceedings of the Eighth Conference on Participatory Design, vol. 1 (July 2004)

7. Ramsey, G., et al.: New Ownership New Responsibilities: Review of Education in the Groote Eylandt and Bickerton Island Region. Terteducon Pty Ltd. (July 2009)

8. Brasche, I.: Cultural resilience and social wellbeing: A case for research on Groote Eylandt. Australian Aboriginal Studies Journal (2), 93-98 (2008)

9. FAHCSIA, Department of Families, Housing, Community Services and Indigenous Affairs, Closing the Gap: The Indigenous Reform Agenda, Australian Government (2009), http: / /www . fahcsia.gov.au/sa/indigenous/progserv/ctg/Pages / default.aspx (access March 23, 2013)

10. Irani, L., Vertesi, J., Dourish, P., Philip, K., Grinter, R.E.: Postcolonial computing: a lens on design and development. In: Proceedings of the 28th International Conference on $\mathrm{Hu}-$ man Factors in Computing Systems, pp. 1311-1320. ACM (April 2010)

11. Indigenous Protected Areas, Australian Government, http://www. environment. gov.au/indigenous / ipa/index.html (accessed on March 23, 2013)

12. Ayakwa newsletter, Anindilyakwa Land Council, http://www.anindilyakwa. com.au/periodicals-and-annual-reports (accessed on March 23, 2013)

13. Ranger video, http://www.environment.gov.au/indigenous/public ations/video-anindilyakwa.html (accessed on March 23, 2013)

14. Winschiers, H.: The Challenges of Participatory Design in a Intercultural Context: Designing for Usability in Namibia. In: PDC, pp. 73-76 (January 2006)

15. Winschiers-Theophilus, H., Chivuno-Kuria, S., Kapuire, G.K., Bidwell, N.J., Blake, E.: Being participated: a community approach. In: Proceedings of the 11th Biennial Participatory Design Conference, pp. 1-10. ACM (November 2010)

16. http://en.wikipedia.org/wiki/Songline 